\title{
Pulmonary function in infants with neonatal chronic lung disease with or without hyaline membrane disease at birth
}

\author{
I.T. Merth*, J.P. de Winter*+, H.M. Zonderland**, G.J.J.M. Borsboom+, P.H. Quanjer ${ }^{+}$
}

Pulmonary function in infants with neonatal chronic lung disease with or without hyaline membrane disease at birth. I.T. Merth, J.P. de Winter, H.M. Zonderland, G.J.J.M. Borsboom, P.H. Quanjer. @ERS Journals Ltd 1997.

ABSTRACT: We studied whether neonatal chronic lung disease (NCLD), hyaline membrane disease (HMD) and differences in ventilatory support affected pulmonary function during the first year of life, in 65 infants born prematurely. The relationship between body weight and oxygen consumption $\left(V^{\prime} \mathrm{O}_{2}\right)$ was also analysed.

The study comprised 14 infants without cardiorespiratory disease, 19 infants with HMD but without NCLD, 9 infants with NCLD without prior HMD, and 23 infants with NCLD following HMD. At 6 and 12 months corrected postnatal age, static respiratory system compliance $\left(C_{\mathrm{rs}}\right)$ was measured by weighted spirometry and the functional residual capacity by closed circuit helium dilution (FRCHe) combined with assessment of ventilation distribution from the mixing index (MI). Ventilatory support during the first 5 days of therapy was quantified from peak inspiratory pressure (PIP), mean airway pressure (MAP) and fractional inspiratory concentration of oxygen $\left(\mathrm{F}, \mathrm{O}_{2}\right)$.

Infants with NCLD had a shorter duration of gestation and lower birth weight than those without $\mathrm{NCLD}$ (Wilcoxon, $\mathrm{p}=\mathbf{0 . 0 0 2}$ and $\mathrm{p}=\mathbf{0 . 0 0 1}$, respectively). Pulmonary function at 6 and 12 months corrected age was not different between NCLD infants with or without HMD at birth. Infants with NCLD had lower $C_{\mathrm{rs}}$ and MI than those without NCLD (analysis of variance (ANOVA), p<0.011), but their FRCHe was not different. $V^{\prime} \mathrm{O}_{2}$ adjusted for body weight was comparable in the four groups. PIP and $F \mathrm{I}, \mathrm{O}_{2}$ were higher (Wilcoxon, $\mathrm{p}<0.01$ ) in the NCLD infants than in those with HMD alone, but MAP was not different. Except for $\mathrm{FI}_{1}, \mathrm{O}_{2}$, these indices were not different among the infants with NCLD.

We conclude that birth weight is the major determinant of the development of neonatal chronic lung disease. At 6 and 12 months corrected age, the abnormal pulmonary function is not associated with prior hyaline membrane disease. Eur Respir J 1997; 10: 1606-1613.
Depts of *Paediatrics, +Physiology and **Radiology, Leiden University, The Netherlands.

Correspondence: I.T. Merth

Dept of Paediatrics

Leiden University

P.O. Box 9600

2300 RC Leiden

The Netherlands

Keywords: Bronchopulmonary dysplasia hyaline membrane disease oxygen consumption pulmonary function radiological score ventilatory support

Received: August 51996

Accepted after revision April 211997

Supported by research grant (No. 90.32) from the Nederlands Astma Fonds (Netherlands Asthma Foundation)
The clinical and radiological picture of bronchopulmonary dysplasia (BPD) following prolonged mechanical ventilation and administration of high concentrations of oxygen for hyaline membrane disease (HMD), described in 1967, has become relatively rare [1]. With the advent of: antenatal corticosteroids; more gentle application of mechanical ventilation; judicious administration of fluids, nutrients and oxygen; early closure of a patent ductus arteriosus; and surfactant administration, a milder form is now more prevalent [2]. The term neonatal chronic lung disease (NCLD) is currently preferred [3]. Mostly because of the increased number of surviving infants with shorter gestation $[4,5]$, the estimated incidence of NCLD of about $30 \%$ of all ventilated newborns has not changed since the original description of BPD [6]. NCLD is now the most prevalent chronic respiratory disorder of infancy.

Expectations of a decrease in the incidence of NCLD as a result of new treatments like surfactant administration to the high-risk group [7] and more sophisticated artificial ventilation [8], have not as yet been met, although new techniques are being developed to meet the challenge [9]. Moreover, a population of very small preterm babies has recently been recognized who initially have no or only mild pulmonary disease requiring no respiratory support, but subsequently develop NCLD [3, 5, 10], suggesting that respiratory support is not a prerequisite for developing NCLD $[6,11,12]$.

Studies published so far have described abnormal pulmonary mechanics in infants who developed NCLD following ventilatory treatment for HMD [13-20]. Abnormal respiratory function is frequently seen as a consequence of lung damage associated with the level of treatment. On the other hand, therapeutic intervention is likely to be necessary if immaturity or prematurity are associated with compromised respiratory function at birth [21]. Only one study included both ventilated and nonventilated preterm infants [17]; in that study asymptomatic infants had normal lung function by the age of $1 \mathrm{yr}$. At school age in children born prematurely, airway diameter, as inferred from forced expiratory flows, was related only to birth weight and not to the level of respiratory therapy at birth [22, 23].

In the present study we analysed the association between a history of HMD, difference in ventilatory support 
and the pulmonary function at 6 and 12 months corrected age in infants with NCLD. Infants with HMD who did not develop NCLD, and infants born prematurely without cardiorespiratory problems served as controls. Because an increased metabolic rate has been suggested as the basis of the growth failure often seen in infants with NCLD [24], the relationship between the metabolic rate assessed by oxygen consumption $\left(V^{\prime} \mathrm{O}_{2}\right)$ and body weight was also studied.

\section{Materials and methods}

\section{Subjects}

We studied 32 infants with and 33 without NCLD, during the first year of life. At 36 weeks postconceptional age all infants with NCLD required additional oxygen to correct hypoxaemia when breathing room air [25], had clinical signs of chronic respiratory distress and had an abnormal chest radiograph according to EDWARDS [26]; of these, 23 infants were diagnosed as having HMD (HMD+/NCLD+) within hours after birth according to standard clinical, laboratory and radiological criteria [27]. The remaining nine infants with NCLD showed no clinical and radiological signs of lung disease during the first week of life; they gradually developed chronic respiratory insufficiency, commencing 1 to 4 weeks postnatally, requiring mechanical ventilation (HMD-/NCLD+). The diagnosis of NCLD was established by a neonatologist caring for the infant when other causes of chronic lung disease (infection, recurrent aspiration, etc.) had been excluded. Of the 33 infants without NCLD, 19 had HMD at birth (HMD+/NCLD-), and 14 never experienced any cardiorespiratory problems (HMD-/NCLD-). Fourteen infants were known to have received steroids antenatally. Of these infants, five developed HMD only, four NCLD only and five developed NCLD following HMD. Fourteen infants were treated postnatally with different courses of corticosteroids because of NCLD. Four of these infants did not have HMD, and 10 developed NCLD following HMD.

During the first 5 days of ventilatory support (timecycled, pressure-limited) the occurrence of a patent ductus arteriosus requiring indomethacin or surgical treatment, infection proven by a positive blood culture, and a pneumothorax, were recorded. Two infants with NCLD without HMD received one dose of porcine surfactant directly after birth as they took part in a randomized, doubleblind trial of prophylactic surfactant administration. Since that trial, surfactant is administered at our department only if indicated by clinical and radiological signs of HMD [27]. The study was approved by the Medical Ethics Committee of the University Hospital Leiden, and informed parental consent was obtained for the participation of the infants.

\section{Equipment}

Depending on the size of the infant, one of two watersealed spirometers (deadspace volumes: 520 and 670 $\mathrm{mL}$, respectively) were used [28]. The spirometers had a $\mathrm{CO}_{2}$ absorber unit, and a blower providing sufficient flow to prevent rebreathing from the instrumental deadspace; oxygen was supplied to meet metabolic demands.
Pressure changes were measured via a side port in the face mask using a differential pressure transducer and amplifier (Validyne MP45 and model MC1-3, respectively; Validyne Corp., Northridge, CA, USA). Helium concentration was measured by heat conductivity (Lode Instruments N.V., Groningen, The Netherlands). The volume, helium and pressure signals were recorded on a multichannel recorder (Linseis, LG5 10, Selb, Germany).

\section{Methods}

Pulmonary function was assessed by measuring the static compliance of the respiratory system $(C \mathrm{rs})$ by weighted spirometry, the functional residual capacity by closed circuit helium dilution (FRCHe), and the distribution of ventilation from the mixing index (MI) [29]. We compared pulmonary function between infants at a median postconceptional age of 59 (25-75\% range: 57-63) and 86 (25-75\% range: 80-91) weeks, corresponding to 22 (25-75\% range: $20-26)$ and $49(25-75 \%$ range: 43-54) for gestation-corrected postnatal weeks (corrected postnatal age in weeks $=$ postconceptional age in weeks minus 37 , i.e. 37 weeks being considered full-term). Forty eight of the 65 infants were tested at both occasions, nine only at the first and eight only at the second occasion (table 1). Infants were tested when clinically stable, without intercurrent infection of the respiratory tract. Only infants with NCLD were on maintenance medication (bronchodilators or diuretics), nine at the first, three at the second measurement. The medication was discontinued at least $12 \mathrm{~h}$ prior to testing. Measurements were made during spontaneous breathing, postprandially and under chloral hydrate sedation (50-100 $\left.\mathrm{mg} \cdot \mathrm{kg}^{-1}\right)$. When the infant required supplemental oxygen, the $\mathrm{O}_{2}$ concentration in the spirometer circuit was increased, so as to keep transcutaneously measured arterial oxygen saturations above $95 \%$ during the measurements (Pulse Oxymeter, Type 1.1.9.0.; Nellcor Inc., Hayward, CA, USA). Silicon putty (George C. Bishop Co., USA) was used to accomplish an air-tight seal at the edges of the mask (Rendell-Baker type, Laerdal No. 1, Norway). Infants were lying supine with the head end elevated approximately $30^{\circ}$ relative to horizontal and the neck held in a neutral position by placing a foam ring under the occiput. The $\mathrm{FRCHe}$ was measured first, followed by the assessment of the $C$ rs. Following the testing session, the crown-heel length of the infant was measured using an infant stadiometer; the mean of two measurements is reported.

Table 1. - Number of infants measured at 6 and 12 months, according to diagnosis

\begin{tabular}{lcccr}
\hline & $\begin{array}{c}\text { Measured } \\
\text { at } 6 \\
\text { and } 12 \\
\text { months } \\
\mathrm{n}\end{array}$ & $\begin{array}{c}\text { Measured } \\
\text { at } 6 \\
\text { months } \\
\text { only } \\
\mathrm{n}\end{array}$ & $\begin{array}{c}\text { Measured } \\
\text { at } 12 \\
\text { months } \\
\text { only } \\
\mathrm{n}\end{array}$ & $\begin{array}{c}\text { Total } \\
\text { HMD-/NCLD- }\end{array}$ \\
\hline HMD+/NCLD- & 18 & 5 & 2 & 14 \\
HMD-/NCLD+ & 8 & 0 & 1 & 19 \\
HMD+/NCLD+ & 15 & 0 & 1 & 9 \\
\hline Total & 48 & 4 & 4 & 23 \\
\hline
\end{tabular}

HMD: hyaline membrane disease; NCLD: neonatal chronic lung disease; -: absent; +: present. 
Functional residual capacity (FRCHe). The measurement method has been described in detail elsewhere [30]. After defining a stable end-expiratory level by adjusting the oxygen flow into the spirometer, the infant was switched into the circuit at or near end-expiration. If the infant was not switched in at end-expiratory volume this was taken into account in the computation of the FRCHe. The effect of increased oxygen concentration in the spirometer on the helium read-out when the $F \mathrm{I} \mathrm{O}_{2}>0.21$ was taken into account. To accommodate slow gas mixing, at least $5 \mathrm{~min}$ were allowed for helium equilibration to occur. To compensate for inadequate oxygen supply and for the slight uptake of helium in blood during the test, the final concentration of helium was obtained by extrapolating the terminal linear portion of the tracing to the onset of decline in helium concentration [30]. Absence of leaks during gas mixing was established by placing a weight on the bell, generating a pressure of $0.3 \mathrm{kPa}\left(2.94 \mathrm{cmH}_{2} \mathrm{O}\right)$. If feasible, measurements were repeated after at least $5 \mathrm{~min}$, so that the helium had been washed out of the lungs. Reported values are that of a single measurement or the mean of up to four (on average two) technically acceptable measurements (i.e. equilibration time at least $5 \mathrm{~min}$, no leak detected, behaviourally quiet sleep suggested by stable end-expiratory level with regular frequency and tidal volume). The single determination standard deviation was $8 \%$ [31]. Volumes were corrected to body temperature and ambient pressure, and saturated with water vapour (BTPS) conditions.

Respiratory system compliance $(\mathrm{C} r s)$. Weights generating pressures of $0.14 \mathrm{kPa}\left(1.37 \mathrm{cmH}_{2} \mathrm{O}\right)$ and $0.30 \mathrm{kPa}$ $\left(2.94 \mathrm{cmH}_{2} \mathrm{O}\right)$, respectively, were placed on the spirometer bell in random order 3-10 times, with and without the subject connected to the spirometer. In the former case, the weight was left in place for at least $30 \mathrm{~s}$. The slope of the volume-pressure relationship of the lungspirometer system was derived from linear regression of volume deflections on applied pressures. $C$ rs was obtained by subtracting the compliance of the spirometer from that of the subject-spirometer system [32]. Reported values are means of two repeated measurements. The single determination standard deviation was $13 \mathrm{~mL} \cdot \mathrm{kPa}^{-1}$ [31]. Volume and pressure changes were calibrated before and after each testing session.

Mixing index (MI). The ratio of the ideal to the actual number of breaths to achieve $90 \%$ of the final helium concentration while measuring the $\mathrm{FRCHe}$ was calculated according to BATES and CHRISTIE [29]. In establishing the time required to achieve $90 \%$ gas mixing, account was taken of the response time of the helium analyser. Reported values are those of one or the mean of up to four assessments (on average two assessments). The single determination standard deviation was 9\% [31].

Oxygen consumption $\left(\mathrm{V}^{\prime} \mathrm{O}_{2}\right)$. Uptake of oxygen was assessed at least once from the volume change after closing the oxygen inlet of the spirometer for on average 90 (range 60-120) s. The measured volume was then corrected to standard temperature, pressure, dry (STPD) conditions. Reported values are means of two assessments.

Quantification of ventilatory support. Uncomplicated hyaline membrane disease resolves by the end of the first week of life [27]. Ventilator therapy for HMD might contribute to the development of chronic lung disease $[6,11,12]$. Therefore, the ventilator settings and the fractional inspiratory oxygen concentration $\left(F \mathrm{I}, \mathrm{O}_{2}\right)$ were noted from the ward sheets every $2-4 \mathrm{~h}$ during the first 5 days after endotracheal intubation. The peak inspiratory pressure (PIP), the mean airway pressure (MAP) [33] and the $F \mathrm{I}_{1} \mathrm{O}_{2}$ were averaged over the number of hours the endotracheal tube was in place during the first 5 days (PIPavg, MAPavg, $F I_{1} \mathrm{O}_{2}$,avg). The maximal peak inspiratory pressure (PIPmax), the maximal mean airway pressure (MAPmax) and the maximal fractional inspiratory oxygen $\left(F_{\mathrm{I}}, \mathrm{O}_{2}, \mathrm{max}\right)$ during this period were also recorded. In addition, the total duration of both the intermittent positive pressure ventilation and the need for additional oxygen $\left(F \mathrm{I}_{2} \mathrm{O}_{2}>0.21\right)$ to keep transcutaneously measured arterial oxygen saturations above $92 \%$ were noted. Because not all infants were treated in our hospital at the time ventilatory support was initiated, data on ventilatory therapy during the first 5 days were available in 14 NCLD-/HMD+ infants, in 15 NCLD+/HMD+ infants, and in 7 NCLD+/HMD- infants.

Radiological score. Anteroposterior chest radiographs of the infants with NCLD taken at 36 weeks postconceptional age were scored according to EDWARDS [26] by one of the authors, who was unaware of whether HMD was present or not.

\section{Statistical analysis}

Analyses were performed with the Statistical Analysis System (SAS) package (SAS Institute, Carey, NC, USA). The scatter of $C$ rs increased with length; a logarithmic transformation of the data stabilized the variance. No transformation was required for the $\mathrm{MI}, V^{\prime} \mathrm{O}_{2}$ or $\mathrm{FRCHe}$. Differences between groups were studied by analysis of covariance at 6 and 12 months corrected postnatal age (analysis of variance (ANOVA)), with NCLD and HMD as factors, and crown-heel length and body weight as covariates (SAS GLM procedure). Because of the unequal number of observations in the groups, least squares means and their $95 \%$ confidence intervals are reported. The Wilcoxon rank sums test was used in situations where the assumptions underlying the analysis of variance were not met. Data on ventilatory support during the first 5 days were tested for differences between the NCLD+/HMD+ and NCLD-/HMD+ groups, and between the NCLD+/HMD+ and NCLD+/HMD- groups, using the Wilcoxon rank sums test or the Chi-square test, where appropriate. A p-value of less than 0.05 was regarded as statistically significant. The approximate power of the F-test applied to differences between groups with and without NCLD was assessed with NCSS PASS (Hintze JL. Version 1.0, Kaysville, UT, USA).

\section{Results}

Clinical characteristics of the groups of infants are summarized in table 2 . There was a predominance of males among infants with HMD and/or NCLD. The duration of gestation was shorter and the birth weight was lower in those who developed NCLD than in those who did not (Wilcoxon rank sums test, $\mathrm{p}=0.002$ and $\mathrm{p}=0.001$, respectively). Among infants with NCLD, birth weight 
was lower in the group without HMD (table 2, Wilcoxon, $\mathrm{p}=0.0031$ ), unlike gestational age (table 2, Wilcoxon, $\mathrm{p}=0.81$ ). Among infants without NCLD there was no difference in birth weight or the duration of gestation (Wilcoxon, $\mathrm{p}=0.13$ and $\mathrm{p}=0.35$, respectively) between those with or without HMD. The duration of mechanical ventilation and administration of oxygen was comparable in infants with NCLD; the $F \mathrm{I}, \mathrm{O}_{2}$ administered at 36 weeks postconceptional age was not different $(\mathrm{p}=0.45)$.

\section{Pulmonary function}

Table 3 summarizes the results obtained in all infants, expressed as least squares means with $95 \%$ confidence intervals. Note that not all infants were measured both at 6 and 12 months (table 1). Body weight or length is frequently used to correct pulmonary function data for size. In NCLD, body weight is known to be low for body length, so that correction for weight is inappropriate. There were no significant differences in crown- heel length between the groups at either of the two occasions, obviating the need to correct the data in table 3 for body length. $C_{\text {rs }}$ and FRCHe are also shown as a function of crown-heel length at 6 and 12 months (fig. $1)$. At both ages, $C$ rs and MI were lower in infants who developed NCLD than in those who did not (table 3, fig. 2. ANOVA, $\mathrm{p}<0.011$ ), but a prior history of HMD did not affect $C$ rs and MI values. These findings did not change after adjustment for crown-heel length. After NCLD was accounted for, $C$ rs at 12 months was related to birth weight (ANOVA, $\mathrm{p}=0.035$ ) and gestational age $(\mathrm{p}=0.0019)$. The FRCHe was not different between any of the groups at 6 or at 12 months corrected age (table 3, figs. 1 and 2), whether or not adjustment for body size was made. Also, the oxygen consumption adjusted for body weight (as an index of metabolic cell mass) was not different at 6 and 12 months of corrected age between any of the groups (table 3, fig. 3). Using an $\alpha=0.05$, differences between infants with and without NCLD could be detected with a power of $90 \%$ or

Table 2. - Characteristics of the infants

\begin{tabular}{|c|c|c|c|c|c|c|c|c|}
\hline \multirow[b]{2}{*}{ Parameter } & \multicolumn{4}{|c|}{ NCLD- } & \multicolumn{4}{|c|}{ NCLD+ } \\
\hline & & HMD- & & HMD+ & & HMD- & & HMD+ \\
\hline $\mathrm{n}$ & & 14 & & 19 & & 9 & & 23 \\
\hline Gender $\mathrm{M} / \mathrm{F}$ & & $7 / 7$ & & $13 / 6$ & & $6 / 3$ & & $17 / 6$ \\
\hline Gestational age weeks & 30.8 & $(26.4-36.0)$ & 31.0 & $(27.3-33.6)$ & 29.1 & $(25.0-30.6)$ & 29.0 & $(24.8-33.4)$ \\
\hline Birth weight $\mathrm{kg}$ & 1.73 & $(0.80-2.58)$ & 1.24 & $(0.79-2.21)$ & 0.73 & $(0.53-1.09)$ & 1.07 & $(0.76-1.89)$ \\
\hline PIPavg $\mathrm{kPa}^{*}$ & & - & 1.38 & $(0-2.07)$ & 1.49 & $(0.17-2.05)$ & 1.80 & $(1.15-2.77)$ \\
\hline PIPmax $\mathrm{kPa} *$ & & - & 1.86 & $(1.17-2.94)$ & 2.15 & $(1.27-2.94)$ & 2.45 & $(1.96-3.92)$ \\
\hline MAPavg $\mathrm{kPa}^{*}$ & & - & 0.55 & $(0-0.65)$ & 0.58 & $(0.46-0.62)$ & 0.62 & $(0.51-0.66)$ \\
\hline MAPmax $\mathrm{kPa}^{*}$ & & - & 0.77 & $(0.54-1.34)$ & 0.73 & $(0.59-2.48)$ & 0.78 & $(0.69-1.19)$ \\
\hline$F_{\mathrm{I}, \mathrm{O}_{2}, \text { avg }}$ & & - & 0.32 & $(0.21-0.48)$ & 0.37 & $(0.22-0.53)$ & 0.46 & $(0.16-0.90)$ \\
\hline$F_{\mathrm{I}, \mathrm{O}_{2}}$, max & & - & 0.74 & $(0.21-1.0)$ & 0.70 & $(0.5-1.0)$ & 1.0 & $(0.5-1.0)$ \\
\hline IPPV duration days & & - & 3 & $(1-15)$ & 28 & $(3-60)$ & 24 & $(8-46)$ \\
\hline$F_{\mathrm{I}, \mathrm{O}_{2}}>0.21$ duration weeks & & - & 0.7 & $(0.14-2.42)$ & 32 & $(11-147)$ & 18 & $(6-212)$ \\
\hline$F_{\mathrm{I}, \mathrm{O}_{2}}$ at 36 weeks & & - & & - & 0.27 & $(0.24-0.40)$ & 0.29 & $(0.23-0.58)$ \\
\hline Edwards score at 36 weeks & & - & & - & 4.0 & $(1-5)$ & 4.5 & $(1-8)$ \\
\hline
\end{tabular}

Values are presented as absolute number or as median, with range in parenthesis. *: during the first 5 days of treatment. n: number of infants; HMD: hyaline membrane disease; NCLD: neonatal chronic lung disease; PIP: peak inspiratory pressure; IPPV: intermittent positive pressure ventilation; MAP: mean airway pressure; $F \mathrm{I}, \mathrm{O}_{2}$ : fractional inspired oxygen; M: male; $\mathrm{F}$ : female; avg: average; max: maximal; -: absent; +: present.

Table 3. - Body size and pulmonary function variables at 6 and 12 months corrected age

\begin{tabular}{|c|c|c|c|c|c|c|c|c|c|}
\hline \multirow[b]{2}{*}{ Parameter } & \multicolumn{4}{|c|}{ NCLD- } & \multicolumn{4}{|c|}{ NCLD+ } & \multirow[b]{2}{*}{ p-value } \\
\hline & & HMD- & & HMD+ & & HMD- & & HMD+ & \\
\hline \multicolumn{10}{|l|}{6 months } \\
\hline & & 12 & & 18 & & 8 & & 19 & \\
\hline Weight $\mathrm{kg}$ & 7.1 & $(6.4-7.8)$ & 6.7 & $(6.1-7.3)$ & 5. & $(4.7-6.4)$ & 6.2 & $(5.7-6.8)$ & 0.004 \\
\hline Length $\mathrm{cm}$ & 63.6 & $(61.0-66.1)$ & 64.1 & $(62.0-66.1)$ & 60. & $(57.3-63.5)$ & 62.9 & $(60.8-64.9)$ & 0.08 \\
\hline$C_{\mathrm{rs}} \mathrm{mL} \cdot \mathrm{kPa}^{-1}$ & 69.0 & $(52.5-90.3)$ & 70.4 & $(56.4-87.8)$ & 33. & $(24.1-46.5)$ & 45.4 & $(36.7-56.2)$ & 0.0001 \\
\hline Mixing index $\%$ & 53 & $(48-59)$ & 49 & $(44-54)$ & 36 & $(29-44)$ & 33 & $(28-38)$ & 0.0001 \\
\hline $\mathrm{FRCHe} \mathrm{mL}$ & 148 & $(128-167)$ & 142 & $(126-158)$ & 134 & $(110-158)$ & 149 & $(133-165)$ & 0.72 \\
\hline $\begin{array}{l}V^{\prime} \mathrm{O}_{2} \mathrm{~mL} \cdot \mathrm{min}^{-1} * \\
12 \text { months }\end{array}$ & 55 & $(51-58)$ & 54 & $(51-57)$ & 52 & $(49-57)$ & 55 & $(52-58)$ & 0.74 \\
\hline & & 9 & & 19 & & 9 & & 19 & \\
\hline Weight $\mathrm{kg}$ & 9.1 & $(8.3-9.8)$ & 9.0 & (8.4-9. & 8. & $(7.5-9.0)$ & 9.0 & $(8.4-9.5)$ & 0.18 \\
\hline Length $\mathrm{cm}$ & 72.2 & $(70.0-74.4)$ & 74.3 & $(72.7-75.8)$ & 71. & $(69.7-74.0)$ & 74.2 & $(72.7-75.7)$ & 0.81 \\
\hline$C_{\mathrm{rs}} \mathrm{mL} \cdot \mathrm{kPa}^{-1}$ & 79.0 & $(58.4-107.7)$ & 108.5 & $(87.5-132.7)$ & 67.8 & (50.4-91.1) & 64.2 & $(52.3-78.7)$ & 0.011 \\
\hline Mixing index \% & 64 & $(55-73)$ & 59 & $(52-65)$ & 42 & $(32-52)$ & 39 & $(32-45)$ & 0.0001 \\
\hline FRCHe $\mathrm{mL}$ & 189 & $(160-218)$ & 212 & $(192-232)$ & 210 & $(179-241)$ & 225 & $(205-245)$ & 0.19 \\
\hline$V^{\prime} \mathrm{O}_{2} \mathrm{~mL} \cdot \mathrm{min}^{-1 *}$ & 76 & $(70-82)$ & 72 & $(68-76)$ & 72 & $(66-78)$ & 76 & $(72-80)$ & 0.40 \\
\hline
\end{tabular}

Values are presented as absolute number, or as least squares means, with $95 \%$ confidence interval in parenthesis. *: adjusted for body weight. \#: value of main effect of NCLD in analysis of variance (ANOVA); n: number of infants at the time of study; $C_{\text {rs: }}$ respiratory system compliance; FRCHe: functional residual capacity by helium dilution; $V^{\prime} \mathrm{O}_{2}$ : oxygen consumption. HMD: hyaline membrane disease; NCLD: neonatal chronic lung disease; +: present; -: absent. 
a)

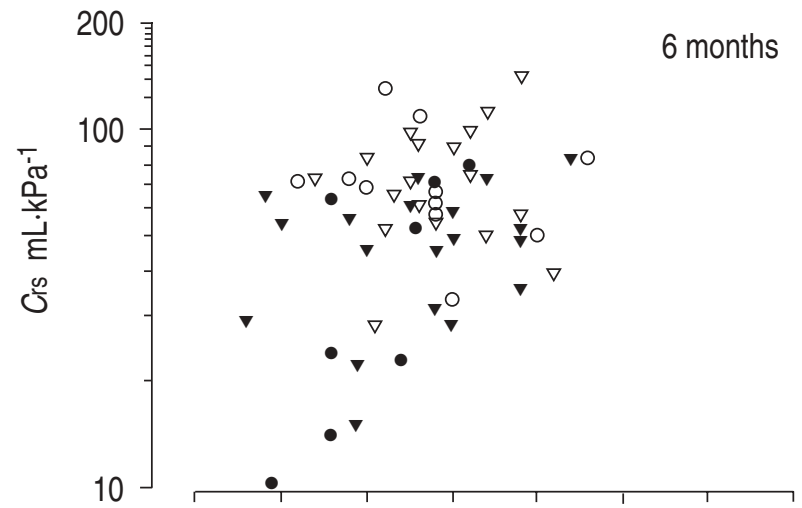

c)

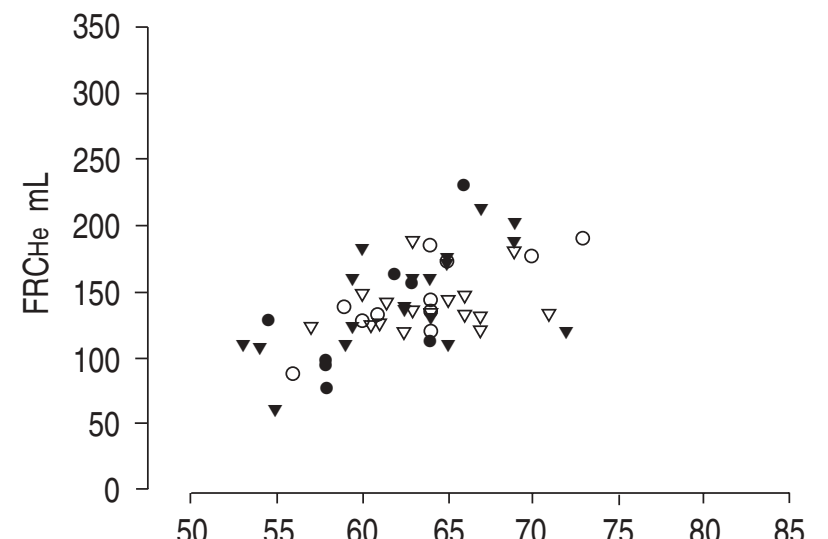

b)

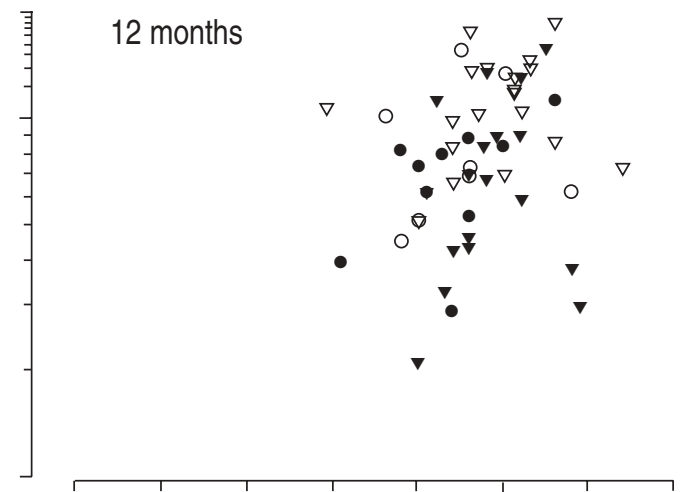

d)

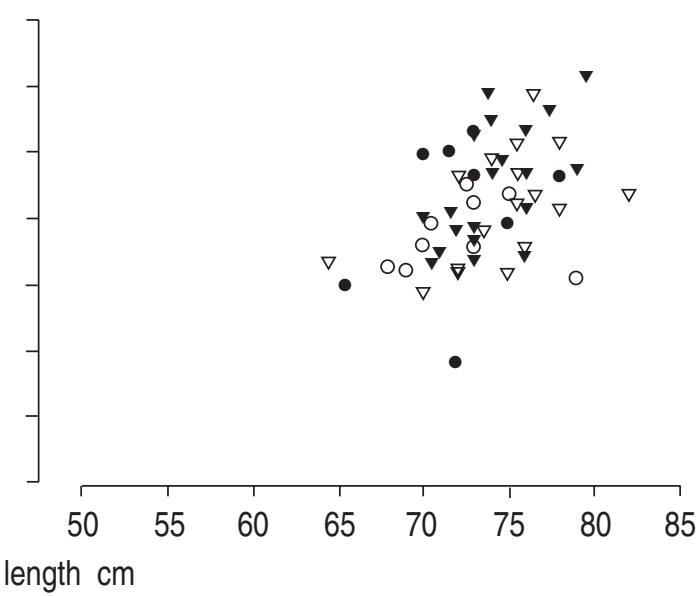

Fig. 1. - a) Relationship between respiratory system compliance $\left(C_{\mathrm{rs}}\right)$, and crown-heel length at 6 months and b) at 12 months corrected postnatal age. c) Relationship between lung volume (FRCHe) and crown-heel length at 6 months and d) at 12 months corrected postnatal age. $\circ$ : hyaline membrane disease (HMD) absent (-)/neonatal chronic lung disease (NCLD)-; $\nabla$ : HMD present (+)/NCLD-; •: HMD-/NCLD+; $\mathbf{v}:$ HMD+/NCLD+.

better for $C_{\mathrm{rs}}$ and the mixing index. For FRC, the standard deviation of group means needed to be twice as large at 12 months, and more than 100 times as large at 6 months, to be able to detect a difference with a power of $70 \%$.

The above findings might be confounded by the fact that some infants were not measured both at 6 and 12 months (table 1). To assess the potential influence the analysis was repeated on paired measurements only $(n=48)$; obviously, this reduced the numbers, and hence the power decreased. The differences noted in table 3 persisted, although the difference in $C_{\mathrm{rs}}$, at 12 months

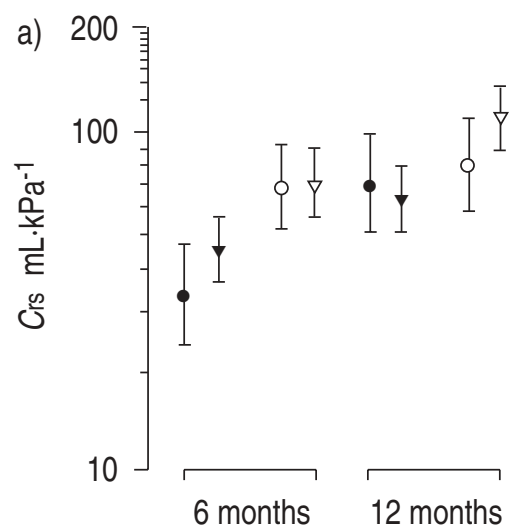

in infants with or without NCLD was of only borderline significance $(p=0.055)$; this may be explained by the decreased power due to fewer subjects. $C_{\text {rs }}$ at 12 months was related to gestational age $(\mathrm{p}=0.030)$, but no longer to birth weight, after NCLD was accounted for. Infants with NCLD had a substantially larger FRCHe (34 mL, p=0.0097) at 12 months than those without. This difference remained after accounting for crownheel length. Ventilation distribution remained abnormal on both occasions in NCLD infants $(\mathrm{p}=0.0001)$, and there were no differences between groups in oxygen consumption corrected for body weight. In the seven infants

Fig. 2. - Least squares means and $95 \%$ confidence intervals of the following pulmonary function variables: a) static respiratory compliance $(C \mathrm{rs})$; b) mixing index; and c) functional residual capacity by closed circuit helium dilution (FRCHe). $\circ$ : hyaline membrane disease (HMD) absent (-)/neonatal chronic lung disease (NCLD)-; $\nabla$ : HMD present (+)/NCLD-; •: HMD-/NCLD+; $\mathbf{v}$ : HMD+/NCLD+. 
a)

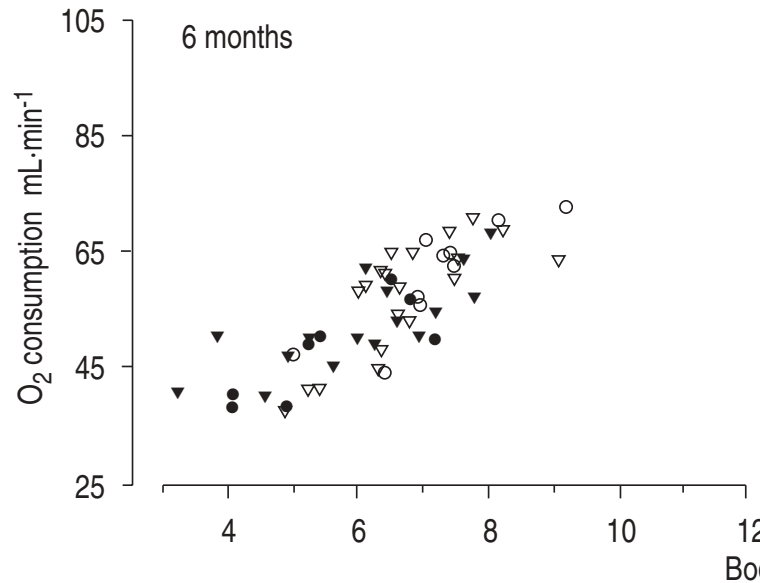

b)

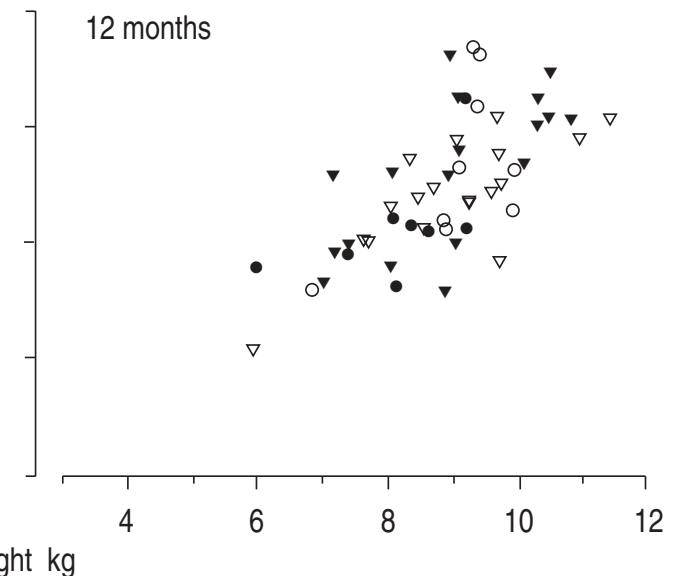

Fig. 3. - The relationship between oxygen consumption and body weight at a) 6 and b) 12 months corrected postnatal age. $\circ$ :hyaline membrane disease (HMD) absent (-)/neonatal chronic lung disease (NCLD)-; $\nabla$ : HMD present (+)/NCLD-; •: HMD-/NCLD+; $\mathbf{~ : ~ H M D + / N C L D + . ~}$

without cardiorespiratory disease, $C$ rs did not increase with age, as expected; this may be a sampling problem, as the group was very small.

\section{Ventilatory support during the first 5 days of therapy}

Data on ventilatory support were available in 36 of 51 ventilated infants (see Methods). Overall, infants who developed NCLD following HMD had a higher level of respiratory support in terms of peak inspiratory pressures (PIPavg and PIPmax; Wilcoxon, $\mathrm{p}=0.004$ and 0.006, respectively) and fractional concentration of oxygen $\left(F \mathrm{I}, \mathrm{O}_{2}\right.$,avg, and $F \mathrm{I}, \mathrm{O}_{2}$, max; $\mathrm{p}=0.01$ in both $)$ than those with HMD who did not develop NCLD (table 2). In the former group, MAPavg were only slightly higher $(\mathrm{p}=0.047)$, whereas MAPmax was comparable with that required by the infants with HMD alone $(\mathrm{p}=0.64)$. These indices of ventilatory support, except for $F \mathrm{I}_{2} \mathrm{O}_{2}$, $\max (\mathrm{p}=0.036)$, were comparable in infants with NCLD with or without prior HMD (table 2). Unlike infection, clinically significant patent ductus arteriosus and pneumothorax were more frequently associated with the clinical course of NCLD following HMD than in those with only HMD (Chisquare, $\mathrm{p}=0.006$ and 0.045 , respectively). No difference was found, however, between the groups of infants with NCLD, with or without prior HMD, in the prevalence of infection, patent ductus arteriosus or pneumothorax.

\section{Edwards score}

The chest radiograph of infants with NCLD at 36 weeks postconceptional age showed fibrotic changes in $96 \%$ of the cases. Hyperinflation, emphysema or the combination of both were seen in $83 \%$ of the radiographs. The Edwards scores were similar between those with and without prior HMD (Wilcoxon, $\mathrm{p}=0.53$; table 2 ).

\section{Somatic growth}

At 6 months corrected age, infants who developed NCLD were slightly smaller than infants without NCLD; the difference was of borderline significance (ANOVA, $\mathrm{p}=0.08$; table 3 ). The crown-heel length was independent of prior HMD. At the corrected age of 12 months, infants with prior HMD were slightly but significantly larger than those without $(\mathrm{p}=0.017)$. Crown-heel length at this age did not differ between the infants without NCLD and those with NCLD (table 3).

At 6 months, body weight in infants with NCLD was lower than in those without (ANOVA, $p=0.004$; table 3 ), before as well as after adjustment for crown-heel length. At 12 months corrected age, this difference had disappeared. Body weight was unrelated to prior HMD at both ages, nor were there any significant interactions between NCLD and HMD with respect to this variable (table 3).

\section{Discussion}

The main findings of our study are that infants with NCLD had a stiffer respiratory system and slower gas mixing at 6 and 12 months corrected age, compared to infants without NCLD. Any differences in level of pulmonary function in the four groups of infants were attributable to the diagnosis of NCLD, but not to that of HMD. The level of ventilatory support was highest in infants with NCLD and prior HMD, in whom, except for infection, the clinical course was more frequently associated with a clinically significant open ductus arteriosus and a pneumothorax than in the other groups of infants. However, in the infants with NCLD, no difference in the level of ventilatory support and the frequency of a patent ductus arteriosus, pneumothorax or infection was found between those with and without prior HMD. Furthermore, the metabolic rate assessed from oxygen consumption in infants with NCLD was comparable to that of infants without NCLD. Infants who developed NCLD had a significantly lower birth weight and shorter period of gestation than infants without NCLD. The NCLD infants were smaller and lighter at 6 months than those without this diagnosis, but had caught up by the age of 12 months.

An attractive feature of using an infant spirometer is that it allows concurrent measurement of $C$ rs, FRCHe and MI [31]. TEPPER et al. [34] were the first to apply weighted spirometry for measuring $C_{\text {rs }}$ in infants [34]. As in the present study, they found a low $C$ rs in infants with NCLD. Although the $C_{\text {rs }}$ in infants with NCLD was consistently less than in those without, it improved considerably between 6 and 12 months. This finding is in agreement with the clinical and radiological course $[11,12]$, and with reports on pulmonary function in 
NCLD infants tested at a comparable age [16-19]. In addition, a decreased compliance is also compatible with radiological and postmortem findings of widespread interstitial fibrosis with thickened airway walls combined with atelectatic and emphysematous parts of the terminal lung units $[26,35,36]$. These structural changes result in persistent maldistribution of ventilation, apparent from the value of MI (table 3, fig. 2) [14, 18]. Crs is known to increase with growth in infants; yet no change was observed in the control group. This is probably due to the small number of infants in this group, especially if only the paired measurements are considered $(n=7)$, rather than to a physiologically plausible cause.

The low $C$ rs, might result in a decreased lung volume. However, we found no differences in $\mathrm{FRCHe}$ between the control and NCLD infants at 6 and 12 months. Lung volume assessed by indicator gas dilution methods has been shown to be low during the first postnatal months in infants with NCLD, attaining normal or increased values during the second part of the first year of life [14, 16-19]. The normal FRC, in as much as it is not due to trapped gas, may be due to overdistension of terminal units combined with a delay in alveolarization. The latter is suggested by postmortem findings of reduced alveolar numbers and the formation of a rudimentary terminal acinus [35-37]. Uneven ventilation with a mix of fibrotic and emphysematous changes is compatible with a somewhat elevated FRC as well as with the decreased $C$ rs and MI (table 3, fig. 2).

Infants with NCLD are known to have a poor weight gain [2]. It has been suggested that infants who do not grow appropriately, in spite of adequate intake of calories, have increased metabolic rates [24]. This has been attributed to increased work of breathing [24], but an improved dynamic compliance and airway conductance after theophylline administration were not associated with a decrease in oxygen consumption in infants with NCLD [38]. In practice, many patients with NCLD are treated with beta-adrenergic drugs and theophylline, both of which increase oxygen consumption [39, 40]. This may well account for reports of increased oxygen consumption [24, 38]. Our findings in infants without medication during the tests suggest normal metabolic rates, as the oxygen consumption adjusted for body weight in infants with NCLD was comparable to that in infants without NCLD, both at 6 months when they had lower weights and at 12 months after they had caught up in growth (table 2, fig. 3).

It has been widely accepted that the level of treatment for HMD may play an important aetiological role in the development of NCLD $[11,12]$. However, NCLD also occurs without prior HMD. Although indices of assisted ventilation were unavailable in $30 \%$ of the ventilated infants, some guarded conclusions can be made. It can be seen in table 2 that a prior history of HMD is not associated with a different level of ventilatory support among infants with NCLD. Similarly, the radiological severity score, the $\mathrm{F}, \mathrm{O}_{2}$ administered at 36 weeks postconceptional age (table 2 ), and the pulmonary function during the first year of life (table 3 , figs. 1 and 2) do not allow the differentiation of these subgroups of infants with NCLD. It seems obvious that the severity of disease determines the level of treatment and not the other way around. NCLD is most likely to develop in infants with an immature respiratory system, which may be more easily damaged by therapeutical interventions. Infants with HMD who went on to develop NCLD, and whose clinical course was more often associated with pulmonary vascular engorgement due to a patent ductus arteriosus, not surprisingly required more respiratory support in the first 5 days of treatment (table 2).

In the present study, there were differences in the level of pulmonary function, assessed at the same postconceptional age, which could be accounted for by NCLD. The power of this study was satisfactory $(\alpha=0.05, \beta \geq 0.9)$ for $C$ rs and MI, but unsatisfactory for FRC. After allowing for NCLD, birth weight and gestational age were unrelated to pulmonary function, except for $C_{\mathrm{rs}}$ at 12 months. Infants with NCLD, particularly those without prior HMD, had the lowest birth weights (table 2). Our findings do suggest that the most plausible chain of events is that the lowest birth weights are associated with the greatest lung immaturity and hence with the highest risk of developing HMD and NCLD [11]. Whilst HMD and NCLD lead to more ventilatory support, which in turn is likely to contribute to a compromised ventilatory function, the level of treatment is not the primary cause of pulmonary disease. Indeed, long-term follow-up studies on lung function of children born prematurely suggest that neither the initial lung disease nor its treatment are risk factors for small airway calibre at school age, unlike a low birth weight $[22,23]$. It is remarkable that the group with the lowest birth weight developed NCLD without prior HMD (table 2); we have no explanation for this finding.

In conclusion, we have found that infants with neonatal chronic lung disease with and without prior hyaline membrane disease at birth were indistinguishable on the basis of their pulmonary function during the first year of life. No difference was found in the ventilatory support required during the first 5 days of therapy. Infants with neonatal chronic lung disease had a shorter duration of gestation and lower birth weight than those who did not develop neonatal chronic lung disease. These findings suggest that intra-uterine developmental delay may be a more important determinant for acquiring neonatal chronic lung disease and associated abnormal pulmonary function, than hyaline membrane disease.

Acknowledgements: The authors are indebted to the parents for allowing the infants to take part in this study. The enthusiastic assistance of P. van Rhijn, J.T. Keijer, J. Dubbeld, W.C.M. Ligthart, J. Kocken, J. Bruzual, E. Gorlee, M. Bezemer, R. Beuker, A. de Jong and A. van de Bas during the measurements is gratefully acknowledged. The expert technical support of G.J. Verschragen and I.C.W. Olievier was invaluable.

\section{References}

1. Northway WH, Rosan RC, Porter DY. Pulmonary disease following respiratory therapy of hyaline-membrane disease. N Engl J Med 1967; 276: 357-368.

2. Abman SH, Groothuis JR. Pathology and treatment of bronchopulmonary dysplasia. Current Issues. Ped Clin N Am 1994; 41: 277-315.

3. Hudak BB, Egan EA. Impact of lung surfactant therapy on chronic lung diseases in premature infants. Clin Perinatol 1992; 19: 591-602. 
4. Parker RA, Lindstrom DP, Cotton RB. Improved survival accounts for most, but not all, of the increase in bronchopulmonary dysplasia. Pediatrics 1992; 90: 663-668.

5. Kennedy KA. Epidemiology of acute and chronic lung injury. Semin Perinatol 1993; 17: 247-252.

6. Northway WH. Bronchopulmonary dysplasia: then and now. Arch Dis Child 1990; 65: 1076-1081.

7. Pramanik AK, Holtzman RB, Merritt TA. Surfactant replacement therapy for pulmonary diseases. Ped Clin N Am 1993; 40: 913-936.

8. HiFi Study Group. High-frequency oscillatory ventilation compared with conventional mechanical ventilation in the treatment of respiratory failure in preterm infants: assessment of pulmonary function at 9 months of corrected age. J Pediatr 1990; 116: 933-941.

9. Heldt GP, Bernstein G. Patient-initiated mechanical ventilation. In: Boynton BR, Carlo WA, Jobe HA, eds. New therapies for neonatal respiratory failure. A physiological approach. Cambridge, Cambridge University Press, 1994; pp. 152-170.

10. Rojas MA, Gonzalez A, Bancalari E, Claure N, Poole C, Silva-Neto G. Changing trends in the epidemiology and pathogenesis of neonatal chronic lung disease. $J$ Pediatr 1995; 126: 605-610.

11. O'Brodovich HM, Mellins RB. Bronchopulmonary dysplasia: unresolved neonatal acute lung injury. Am Rev Respir Dis 1985; 132: 694-709.

12. Bancalari E. Neonatal chronic lung disease. Part Six. In: Fanaroff AA, Martin RJ, eds. Neonatal-perinatal medicine. St. Louis, Mosby-Year Book, 1992; 861-876.

13. Bryan MH, Hardie MJ, Reilly BJ, Swyer PR. Pulmonary function studies during the first year of life in infants recovering from the respiratory distress syndrome. Pediatrics 1973; 52: 169-178.

14. Watts JL, Ariagno RL, Brady JP. Chronic pulmonary disease in neonates after artificial ventilation: distribution of ventilation and pulmonary interstitial emphysema. Pediatrics 1977; 60: 273-281.

15. Lindroth M, Jonson B, Svenningsen NW, Mortensson W. Pulmonary mechanics, chest X-ray and lung disease after mechanical ventilation in low birth weight infants. Acta Paediatr Scand 1980; 69: 761-770.

16. Morray JP, Fox WW, Kettrick RG, Downes JJ. Improvement in lung mechanics as a function of age in the infant with severe bronchopulmonary dysplasia. Pediatr Res 1982; 16: 290-294.

17. Wong YC, Beardsmore CS, Silverman M. Pulmonary sequelae of neonatal respiratory distress syndrome in very low birthweight infants: a clinical and physiological study. Arch Dis Child 1982; 57: 418-424.

18. Tepper RS, Morgan WJ, Cota K, Taussig LM. Expiratory flow limitation in infants with bronchopulmonary dysplasia. J Pediatr 1986; 109: 1040-1046.

19. Gerhardt T, Hehre D, Feller R, Reifenberg L, Bancalari E. Serial determination of pulmonary function in infants with chronic lung disease. J Pediatr 1987; 110: 448-456.

20. Mallory GB, Chaney H, Mutich RL, Motoyama EK. Longitudinal changes in lung function during the first three years of premature infants with moderate to severe bronchopulmonary dysplasia. Pediatr Pulmonol 1991; 11: 8-14.

21. Thurlbeck WM. Prematurity and the developing lung. Clin Perinatol 1992; 19: 497-519.

22. Chan KN, Noble-Jamieson CM, Elliman A, Bryan EM, Silverman M. Lung function in children of low birth weight. Arch Dis Child 1989; 64: 1284-1293.

23. Galdès-Sebald M, Sheller JR, Grogaard J, Stahlman M.
Prematurity is associated with abnormal airway function in childhood. Pediatr Pulmonol 1989; 7: 259-264.

24. Kurzner SI, Garg M, Bautista D, Sargent CW, Bowman $\mathrm{CM}$, Keens TG. Growth failure in bronchopulmonary dysplasia: Elevated metabolic rates and pulmonary mechanics. J Pediatr 1988; 112: 73-80.

25. Shennan AT, Dunn MS, Ohlsson A, Lennox K, Hoskins EM. Abnormal pulmonary outcomes in premature infants: prediction from oxygen requirement in the neonatal period. Pediatrics 1988; 82: 527-532.

26. Edwards DK. The radiology of bronchopulmonary dysplasia and its complications. Chapter 12. In: Merritt TA, Northway WH, Boynton BR, eds.: Bronchopulmonary dysplasia. Oxford, Blackwell Scientific Publications, 1988; pp. 185-234.

27. Greenough A, Morley CJ, Roberton NRC. Acute respiratory disease in the newborn. In: Roberton NRC, ed. Textbook of neonatology, 2nd Edn. Edinburgh, Churchill Livingstone, 1992; pp. 395-504.

28. Merth IT, Verschragen GJ, Olievier ICW, de Winter JP, Quanjer PhH. Water-sealed spirometer for measurements in newborns and infants. J Appl Physiol 1993; 74(1): 470-475.

29. Bates D, Christie R. Intrapulmonary mixing of helium in health and emphysema. Clin Sci 1950; 9: 17-27.

30. Merth IT, Quanjer PhH, Verschragen GJ. Functional residual capacity by the helium dilution method. In: Dezateux CA, Fletcher ME, Rabette PS, Stanger LJ, Stocks J, eds. A manual of infant lung function testing. London, Portex Anaesthesia, Intensive Therapy and Respiratory Medicine Unit, Institute of Child Health, 1991; pp. 61-82.

31. Merth IT, de Winter JP, Borsboom GJJM, Quanjer PhH. Pulmonary function during the first year of life in healthy infants born prematurely. Eur Respir J 1995; 8: 1141-1147.

32. Merth IT, Quanjer PhH. Respiratory system compliance assessed by the multiple occlusion and weighted spirometer method in non-intubated healthy newborns. Pediatr Pulmonol 1990; 8: 273-279.

33. Dillard RG. Mean airway pressure calculation. J Pediatr 1980; 97: 506-507.

34. Tepper RS, Pagtakhan RD, Taussig LM. Noninvasive determination of total respiratory system compliance in infants by the weighted spirometer method. Am Rev Respir Dis 1984; 130: 461-466.

35. Stocker J. Pathologic features of long-standing "healed" bronchopulmonary dysplasia: a study of 28 3- to 40month-old infants. Human Pathol 1986; 17: 943-961.

36. Margraf LR, Tomashefsky JF, Bruce MC, Dahms BB. Morphometric analysis of the lung in bronchopulmonary dysplasia. Am Rev Respir Dis 1991; 143: 391-400.

37. Hislop AA, Haworth SG. Airway size and structure in the normal fetal and infant lung and the effect of premature delivery and artificial ventilation. Am Rev Respir Dis 1989; 140: 1717-1726.

38. Kao LC, Durand DJ, Nickerson BG. Improving pulmonary function does not decrease oxygen consumption in infants with bronchopulmonary dysplasia. J Pediatr 1988; 112: 616-621.

39. Gerhardt T, McCarthy J, Bancalari E. Effect of aminophylline on respiratory center activity and metabolic rate in premature infants with idiopathic apnea. Pediatrics 1979; 63: 537-541.

40. Newth ChJL, Amsler A, Anderson GP, Morley J. The ventilatory and oxygen costs in the anesthetized rhesus monkey of inhaling drugs used in the therapy and diagnosis of asthma. Am Rev Respir Dis 1991; 143: 766-771. 